\title{
PINTURAS DE DOMINGO MARTÍNEZ EN LA CAPILLA DE LA VIRGEN DE LA ANTIGUA EN LA CATEDRAL DE SEVILLA
}

\author{
por EnRiQue Valdivieso
}

\begin{abstract}
La restauración de la capilla de la Virgen de la Antigua y consiguientemente de las pinturas que adoman sus paredes ha permitido poder observar de cerca estos lienzos que se hallaban situados a gran altura y por lo tanto difícilmente visibles. Se establecen algunas recitificaciones sobre la identidad de varias pinturas, siendo especialmente significativa la referida a la traslación del muro que contenía la imagen de la Virgen. Se refieren también las restauraciones ocurridas con motivo del incendio de 1889.
\end{abstract}

The restoration of the chapel of the Virgen dela Antigua, together with the paintings adorning its walls, has made it possible to examine these works at close hand; previously, they were situated at a great height and therefore difficult to see properly. Some rectifications have been made concerning the identity of several of the paintings, particularly significant being new information about the removal of the wall which contained the image of the Virgin. Reference is also made to restoration work carried out after the fire of 1889 .

La reciente restauración del conjunto pictórico que adorna los muros de la Capilla de la Virgen de la Antigua de la Catedral de Sevilla, nos ha permitido contemplar directamente esta notable serie, que por la considerable altura en que se encuentra dispuesta en su emplazamiento habitual había sido siempre problemática de admirar y de valorar adecuadamente.

Bien sabido es que estas obras fueron realizadas por Domingo Martínez entre 1734 y 1738 bajo el patrocinio del entonces arzobispo de Sevilla Don Luis Salcedo y Azcona, gran devoto de la Virgen, quien además escogió la capilla como lugar de enterramiento ${ }^{1}$.

1. Sobre este conjunto pictórico véase Carrillo y Aguilar, A. Noticia del origen de la milagrosa imagen de nuestra Señora de la Antigua... Sevilla 1738. Carriazo, J.M., Correspondencia de Don Antonio Ponz con el Conde del Aguila. Archivo Español de Arte y Arqueología. 1929, p. 168. Ponz, A., Viaje de España IX. 1876, p. 22. Ceán Bermúdez, A., Diccionario... 1800. p. 75. Colón y Colón, J., Sevilla Artistica. 1844, p. 43. González de León, F., Noticia artistica de Sevilla. Sevilla, 1844, p. 347. Gestoso, J., Sevilla monumental y artistica II. Sevilla, 1892, p. 512. Sánchez Moguel, A., Historia de Nuestra Señora de la Antigua. Sevilla, 1868. Guerrero Lovillo, J., La pintura sevillana en el siglo XVIII. Archivo Hispalense. 1951, p. 36-37. Valdivieso, E., Catálogo de las pinturas de la Catedral de Sevilla. Sevilla, 1978, p. 78-80. Soro, S., Domingo Martinez. Sevilla, 1982. 
Aparte de la intervención de Domingo Martínez en la ejecución de las pinturas, sabemos que por su amplio número y tamaño, el artista hubo de utilizar la ayuda de los miembros de su taller. En ese sentido la primera información que después se ha venido repitiendo de forma sistemática la proporcionó el Conde del Aguila en 1781 cuando señaló ${ }^{2}$ que Andrés Rubira actuó como colaborador de Martínez en la realización de las pinturas, precisando que "manchaba" los cuadros y que Martínez los acababa.

Importante es también señalar que el 24 de marzo de 1889, según informa Gestoso $^{3}$ un incendio acaecido en la capilla, que entonces era lugar de oficinas, alcanzó a varias pinturas de la misma, destruyendo por completo algunas de ellas y dañando seriamente a otras. Al haberse descolgado ahora todo el conjunto ha podido advertirse que el incendio afectó a las situadas en el muro derecho, especialmente las más cercanas a la verja que cierra la capilla. Hay que señalar que entendemos como muro derecho el situado a la derecha del espectador cuando se mira al altar mayor de la capilla. Permite también la contemplación directa de las pinturas emitir una serie de precisiones que vienen a corregir algunas afirmaciones emitidas en el pasado, de las cuales habíamos sido partícipes.

En principio es precidos señalar que la valoración general que habíamos hecho sobre las pinturas y que las consideraba como de "escasa calidad" 4 no es cierta. Podemos justificarnos señalando que la distancia y el polvo nos impidieron realizar una crítica más positiva pero ya existían de antiguo criterios más encomiásticos en ese sentido. Así Ceán Bermúdez ${ }^{5}$ había señalado que estas obras de Martínez eran de lo mejor que había pintado, a pesar de evidenciar que muchos detalles compositivos estaban tomados de estampas. El propio Ceán en 1804 al describir la capilla señala que las pinturas estaban pintadas con destreza y corrección de dibujo, aunque evidenciaban cierto estilo amanerado y advierte plagios derivados de estampas. Vistas ahora las pinturas limpias y con detenimiento puede advertirse que en efecto Martínez empleó en ellas con la habilidad emanante de su buen oficio, constatándose una gran soltura de dibujo no exenta de algunos descuidos técnicos, que el artista daría por buenos, teniendo en cuenta la lejanía en que habían de estar colocadas con respecto al ojo del espectador.

Entre las pinturas situadas en el muro derecho o de la Epístola de la capilla, la que representa La caida del muro que ocultaba la imagen de la Virgen, se dispone en su parte alta, a una distancia de unos veinticinco metros del suelo y vista en su emplazamiento original resulta totalmente imperceptible al espectador a pesar de su gran tamaño ( 395 x $570 \mathrm{cms}$.). Se narra en esta obra el momento en

2. Carriazo, J.M., ob. cit., p. 168.

3. Gestoso, J., ob. cit., p. 512.

4. Valdivieso, E., ob. cit., p. 78.

5. Ceán Bermúdez, ob. cit., p. 75. Id. Descripción artística de la Catedral de Sevilla. Sevilla, 1804, p. 87 
que se produce el hecho prodigioso del desmoronamiento de un muro levantado por los musulmanes para ocultar en la mezquita la imagen de la Virgen de la Antigua que había quedado como resto de la antigua catedral visigoda. La leyenda narra que este episodio acaeció en el momento histórico en que Sevilla estaba sitiada por el ejército de Fernando III y que los musulmanes lo interpretaron como un presagio nefasto y una premonición de la inmediata conquista de la ciudad por parte del Rey Santo ${ }^{6}$.

En la zona media de este muro de la derecha y con tan sólo discreta visión, se dispone otra pintura de tran tamaño ( 402 x $634 \mathrm{cms}$.) que representa La vista nocturna de San Fernando a la Virgen, en la cual se describe el episodio que la piadosa tradición situa el año 1248, durante el cerco de Sevilla, cuando San Fernando logró una noche burlar la vigilancia de los musulmanes y entrar ocultamente en la ciudad. El rey se dirigió hacia la mezquita y logró llegar hasta la imagen de la Virgen de la Antigua donde la veneró hasta el alba, momento en que regresó al campamento cristiano ${ }^{7}$. La contemplación de esta pintura evidencia que fue seriamente dañada en el incendio de 1889 , advirtiéndose una torpe y deficiente restauración en una amplia zona de su parte derecha realizada a finales del siglo XIX como consecuencia del incendio ${ }^{8}$.

Peor suerte aún corrió el San Carpóforo ( 405 x 245 cms.) que estaba situado a la derecha de la pintura anterior, puesto que debió de arder íntegramente y por ello hubo de ser sustituido por otra pintura de igual iconografía que debió ser realizada por el mismo artista que restauró "La Visita". Este pintor, lamentablemente estaba dotado de escasas facultades técnicas, ya que la obra es muy pobre y de burda ejecución. Por fortuna el San Leandro ( 405 x 245 cms.) colocado a la izquierda de "La Visita" no fue alcanzado por el fuego, por lo que muestra intacta la calidad técnica de Martínez, quien hubo de esforzarse especialmente en la ejecución de esta pintura ya que en su rostro colocó los rasgos faciales del arzobispo D. Luis Salcedo y Azcona, patrono de la capilla, quien de esta manera quedaba solemnemente homenajeado en actitud de triunfar sobre la herejía.

También salió indemne del fuego la pintura que representa a Juan Duns Escoto, ( $280 \times 173 \mathrm{cms}$.) situado en la parte baja de este muro derecho, próximo al altar. La presencia en la capilla se justifica por haber sido entusiasta defensor del culto mariano y por ello en la pintura se le aparece la Virgen en

6. Sobre el marco de esta pintura se colocó un tarjetón con la inscripción: A facie mea omnis murus corruit in terram: Ante mi figura todo muro cae a tierra.

7. La inscripción que se puso en un tarjetón sobre el marco de esta pintura es la siguiente: Si subito apparuerit Aurora, umbram mortis arbitrantur (Job, cap 24, v. 17): Si de repente apareciera la aurora piensan que es la sombra de la muerte.

8. La restauración de estas pinturas fue realizada por José Escacena y Diéguez (1855-1909). Cfr. J.M. Serrera, La Virgen de la Antigua. Informes y restauraciones. Siglos XVIII-XIX. Archivo Hispalense, 1990. En prensa. 
agradecimiento por haber defendido el misterio de la Inmaculada Concepción. Sus loas marianas difundidas en sus escritos motivaron que este fraile escocés del siglo XIII, perteneciente a la orden franciscana, fuese llamado "Doctor Mariano", "Doctor de la Inmaculada Concepción" y "Doctor sutil"9.

Otras pinturas de Martínez que estaban colocadas en este muro derecho, próximo a la reja de entrada de la capilla se perdieron totalmente con el incendio. Fueron San Diego de Alcalá curando enfermos ${ }^{10}$, los Arcángeles San Miguel, San Rafael y San Gabriel y los óvalos de Santa Florentina, San Fernando, San Hermenegildo y San Abundio. El San Diego y los óvalos se sustituyeron por mediocres copias de Escacena y los Arcángeles fueron suplidos por una representación de Cristo curando al ciego, que es obra de discreta calidad realizada a mediados del siglo XVII. Es de lamentar que el cuadro de los Arcángeles se perdiera puesto que su iconografía hace pensar que su composición fuese muy atractiva aunque al menos nos queda de ella la descripción que realizaron Carrillo y Aguilar y Sánchez Moguel ${ }^{11}$, quienes mencionan en ella la presencia de los tres Arcángeles seguidos de huestes celestiales, llevando todos pendientes del cuello la venera del Ave María. Señalan los mismos autores con razón, que esta pintura toma su asunto del libro místico Ciudad de Dios de Sor María de Agueda donde se narra cómo los Arcángeles del cielo se hacían presentes ante la Virgen saludándola con el Ave María.

En el muro del Evangelio de la izquierda de esta capilla, se dispone un conjunto similar y contrapuesto en situación y tamaño al del muro derecho. Afortunadamente el incendio de 1889 no afectó tan gravemente a las pinturas aunque algunas quedaron dañadas por el calor y muy oscurecidas por el humo, aparte del polvo acumulado en ellas en los dos siglos y medio en que llevaban allí colgadas.

En la parte superior de este muro izquierdo se dispone La aparición de la Virgen a los musulmanes a través del muro que la ocultaba $(395 \times 571$ cms.). La composición de esta pintura posee un dinámico y tumultuoso movimiento que traduce perfectamente el sentido del episodio de la leyenda, en el que los musulmanes al querer levantar un muro para ocultar la pintura de la Virgen de la Antigua, que había subsistido del derribo de la Catedral visigoda, percibieron aterrados como la imagen se transparentaba

9. En el tarjetón que se colocó en el marco de esta pintura figura la frase: Dignare, me laudare te, Virgo Sacrata: Concédeme alabarte, Virgen sagrada.

10. Según Carrillo y Aguilar, ob. cit., p. 56, San Diego de Alcalá aparecía en la pintura curando las dolencias de los enfermos con el aceite de las lámpara de la capilla de la Virgen de la Antigua que aplicaba con una pluma de ave. Sobre el marco de la pintura figuraba un tarjetón con el siguiente texto: Lampadis, quae collucebat ante Imaginem Beatissimae Dei Genitricis oleo aegrotos inungens sanaverit. Eccles. Offic.: Sanará a los enfermos ungiéndoles con el aceite de la lámpara que alumbraba delante de la imagen de la Santísima Madre de Dios.

11. Carrillo y Aguilar, ob. cit., p. 57. Sánchez Moguel, ob. cit., p. 144. 
merced a los intensos resplandores que emitía, prodigio que les llenó de espanto y confusión ${ }^{12}$.

En la parte media de este muro izquierdo se representa La traslación de la imagen de la Virgen de la Antigua, ceremonia que se realizó el 7 de noviembre de 1578 en el interior de la Catedral y que consistió en el desplazamiento de la pintura de la Virgen que se conservaba en un trozo de muro, en la propia capilla junto a la reja grande, como demuestra Carrillo y Aguilar $^{13}$ a un nuevo altar que se construyó en el presbiterio de la misma capilla.

Con respecto a esta pintura de Martínez nos es necesario realizar una rectificación fundamental ya que en un principio condicionado por la altura y la oscuridad del lienzo creímos que era una de las pinturas que había sufrido las consecuencias del incendio de 1889 y por lo tanto habría sido sustituida por otra ${ }^{14}$. Al verla ahora en el suelo se comprueba que es un original genuino de Domingo Martínez, y que por otra parte es probablemente la pintura más interesante de todo el conjunto. Llama la atención en primer lugar el complejo entramado de andamios, poleas, molinillos, cabestrantes y tornos, ingenios que permiten el traslado del trozo de muro con la figura de la Virgen hasta su altar. Es muy posible que esta complicada operación fuese dirigida por el maestro mayor de la Catedral que en aquellos momentos era Asensio de Maeda ${ }^{15}$. La emotiva traslación aparece contemplada en la pintura por una multitud de personas que el artista ha dispuesto deliberadamente en grupos claramente diferenciados. Así, a la izquierda figura un grupo de eclesiásticos presididos por el arzobispo Don Cristóbal de Rojas Sandoval, en cuyo rostro Martínez colocó los rasgos de D. Luis Salcedo y Azcona. Un nutrido cortejo de clérigos le acompaña pudiéndose sugerir que el que figura a la izquierda sea el retrato de D. Miguel Bucarelli y Ursúa, Deán en la Catedral en 1738 .

A la derecha aparece otro nutrido grupo de personas, éstas de carácter civil, entre las cuales Martínez había querido efigiar al Conde de Barajas, Don Francisco Zapata y Cisneros, al Duque de Medina Sidonia, D. Juan Alonso de Guzmán, al Marqués de Villamanrique y otros miembros de la nobleza sevillana que asistieron a la ceremonia. No sería de extrañar que Martínez aprovechase esta ocasión para retratar en estos personajes, a los principales gobernantes y aristócratas de la ciudad en los momentos en que fueron ejecutadas las pinturas.

12. En el tarjetón situado sobre el marco de esta pintura se colocó la inscripción: Fulgura corruscationem et disipabit eos: Brilla con resplandores y los dispersa.

13. Carrillo y Aguilar, ob. cit., pp. 11-15.

14. Valdivieso, E.: Catálogo de las pinturas de la Catedral de Sevilla, 1978. p. 78-79.

15. Al menos así lo señala Sánchez Moguel, ob. cit., p. 52, quien lo extrae del Acta de Traslación que se guarda en el Archivo de la Catedral, aunque cita al maestro como Alonso de Maeda. 
En el fondo de la composición y a la derecha se advierte cómo aparece abierta la puerta de San Miguel, por donde había de entrar la comitiva, pudiéndose observar por ello, aunque muy difusa la correspondiente fachada de la entonces Casa Lonja ${ }^{16}$.

Flanqueando a esta composición del traslado de la imagen figuran las efigies de San Isidoro y San Laureano ( $405 \times 245 \mathrm{cms}$.), obras que muestran de manera perfecta el estilo de Martínez, advirtiéndose en el primero, captado en actitud de escribir un texto sagrado, que el artista se inspiró para su descripción física en el modelo que Murillo plasmó en su San Isidoro, en la Catedral de Sevilla.

Junto al altar de la Capilla se encuentra el retrato de Sor María Jesús de Agreda, monja franciscana del siglo XVII, que alcanzó notoria fama por haber mantenido correspondencia epistolar con Felipe IV, en la que ofrecía al monarca consejos de carácter moral e incluso políticos; su presencia en la capilla está justificada por haber emitido la frase que señala: "el nombre de Nuestra Señora de la Antigua es el que más le place a la Santísima Virgen de cuantos le dan los cristianos". Esta opinión está recogida en su libro "Mística ciudad de Dios..." 17 cuyo contenido es una vida de la Virgen inspirada fundamentalmente en el texto de los Evangelios apócrifos, lo que motivó que en 1672, dos años después de su publicación, fue prohibida por la Inquisición española y posteriormente por el Santo Oficio, desde 1681 a 1686. Ello no fue óbice para que en 1673 el papa Clemente $X$ la declarase venerable y que desde entonces se la considerase como una de las más importantes exégetas del culto mariano. Su fama trascendió al siglo XVIII con gran repercusión en los ambientes espirituales y es por lo tanto lógico que el arzobispo Salcedo la incluyese en el programa inconográfico de la capilla dada su relevante labor en favor de la Virgen.

En la pintura el artista representó a la Venerable Sor María de Jesús de Agreda en el momento en que se le aparece la Virgen para inspirarle la redacción de su libro, cuyo título aparece perfectamente legible en su portada ${ }^{18}$.

De menor interés y calidad son las pinturas que se disponen en la parte baja de este muro izquierdo. Así ha de valorarse como obra tan sólo discreta en su técnica, la representación de El Venerable Fernando de Contreras presentando cautivos redimidos a la Virgen, obra que testimonia la devoción que este redentor de prisioneros de los musulmanes tenía hacía la Virgen de la Antigua , cuya

16. Sobre el marco de la pintura se colocó un tarjetón con el siguiente texto: Translatum est gaudium terrae. Isai. cap. 24, 8 II: Se ha trasladado la alegría de la tierra.

17. El título del libro es: Mystica ciudad de Dios. Milagro de su omnipotencia y abismo de la Gracia, Historia divina y vida de la Virgen Madre de Dios, Reyna y Señora nuestra Maria Santísima... Manifestada... por la misma Señora a su Esclava Sor Maria de Jesús de Agreda. Fue editado en Madrid en 4 volúmenes en 1670.

18. En el marco figura un tarjetón con el texto: Gloriosa dicta sunt de te Civitas Dei. Psalm. 86, V. 3: Glorias se hablan de ti Ciudad de Dios. 
imagen llevaba siempre consigo. También cuando regresaba a Sevilla una vez finalizadas sus misiones de redención acudía delante de la Virgen con todos los libertos que había rescatado para agradecer su protección y dejar ante ella sus cadenas en testimonio de su libertad. En la figura del venerable Contreras se advierte que su rostro está tomado del que se atribuye a Luis de Vargas y se conserva en la propia Catedral ${ }^{19}$.

Realizados con el hábil oficio que caracteriza a Martínez, están los óvalos que representan a los Santos Luises, cuya devoción se corresponde con el nombre del arzobispo y patronos de la Capilla D. Luis Salcedo y Azcona. Son San Luis de Francia, San Luis de Tolosa, San Luis Gonzaga y San Luis Beltrán.

Según testimónio de Carrillo y Aguilar y Sánchez Moguel ${ }^{20}$ la bóveda de esta capilla de la Virgen de la Antigua estuvo pintada originariamente, por lo que es lógico pensar que esta labor correspondiese a Martínez, siendo realizada en el momento de la decoración entre 1734 y 1738. Según mencionan estos autores en el centro de la bóveda aparecía un sol que emanaba fulgurantes rayos. Dentro del sol aparecía la Paloma del Espíritu Santo rodeada de ángeles, y otros ángeles en torno al astro interpretaban música y arrojaban flores dirigidas obviamente a la Virgen de la Antigua.

Por otra parte Carrillo y Aguilar señala pintadas en las enjutas del arco de entrada a la capilla dos representaciones de San Pío mártir y San Sabino acompañadas de decoración vegetal, obras realizadas seguramente por el propio Martínez, al temple sobre el muro, que actualmente no existen ${ }^{21}$.

La iconografía de las pinturas de la Capilla de la Virgen de la Antigua se completa con otras dos obras, también de Martínez que se guardaban en la sacristía aneja. Ambas son testimonio de la admiración que el obispo profesó a los franciscanos que fueron devotos a la Virgen de la Antigua, siendo en este caso concreto protagonistas de las pinturas San Diego de Alcalá y la Virgen de la Antigua.

En la primera pintura de la sacristía se representa un Milagro de la Virgen de la Antigua ( $140 \times 106 \mathrm{cms}$.). en ella aparece la inscripción: cum ceciderit non colidetur quia suponit manum suam Psalm 36. v. 24. Corresponde este texto en efecto al libro de los Salmos, donde en el capítulo y versículos aparece esta frase cuya traducción es: Aunque caiga no quedará en el suelo porque (Yavé) la mano le sostiene.

La frase sirve de apoyatura bíblica a un milagro que tuvo lugar en la calle Génova de Sevilla en 1615 cuando un niño cayó accidentalmente de un balcón. Su padre que desde la calle pudo contemplar la caida, encomendó al

19. En el marco de la pintura se colocó un tarjetón con el siguiente texto: Qui redempti sunt a Domino revertetur et venient in Sion laudantes. Isai. cap. 59. v. II. Los que han sido redimidos por el Señor vuelven y vienen a Sión alabándole.

20. Carrillo y Aguilar, ob. cit., p. 40. Sánchez Moguel, ob. cit., p. 143.

21. Carrillo y Aguilar, ob. cit., p. 59. Restos de las pinturas murales que cubrian los muros de esta capilla han aparecido, durante el proceso de restauración de la misma, en los laterales del altar. 
niño a la Virgen de la Antigua y milagrosamente el niño llegó indemne al suelo. Este milagro fue también presenciado por San Diego de Alcalá, quien en lo sucesivo se preocupó de propagarlo y ensalzar al mismo tiempo la grandeza de la Virgen.

Otra versión de este milagro que no coincide con la representación de la pintura, narra que un albañil que trabajaba en un andamio de la calle Génova se cayó desde el tejado de una casa, llegando ileso al suelo merced a que durante la caida invocó a la Virgen de la Antigua.

El otro milagro de la Virgen de la Antigua, representado en la sacristía de la capilla y vinculado a San Diego de Alcalá, narra la salvación milagrosa de un niño lograda merced a la intercesión de San Diego de Alcalá. Al igual que en la pintura anterior lleva una inscripción que señala: ambulabat in medio flamae laudans Deo et benedicens Domino. Danl. cp 3, v. 24. El texto pertenece al libro de Daniel y su traducción puede ser: Iba en medio de las llamas alabando a Dios y bendiciendo al Señor.

La pintura describe un episodio acaecido en Sevilla en 1448, en el que una bruja metió en un horno a un niño y que fue salvado por el Santo. Otra versión más próxima al argumento de la pintura señala que en una casa de la calle llamada Horno de las Brujas, un niño huyendo de los golpes de su madre se escondió en el horno de la casa. La madre ignorándolo lo encendió posteriormente y ante los gritos del niño que se abrasaba dentro, salió a la calle en demanda de auxilio. Allí encontró a San Diego, el cual encomendó el niño a la Virgen de la Antigua, encontrándose al entrar en la casa que el niño estaba fuera del horno, sano y salvo.

Como conclusión al comentario general de las pinturas de esta capilla, parece que puede advertirse en ella un programa iconográfico ideado por el arzobispo D. Luis de Salcedo y Azcona con la intención de narrar los episodios más importantes de la historia de la Virgen de la Antigua. Al mismo tiempo situó en ella a los obispos sevillanos de época visigoda, en la cual se creía que se había iniciado el culto a esta Virgen y que por lo tanto la pintura pertenecía a dicha época. Hoy, sin embargo, por sus características de estilo sabemos que es obra fechable a finales del siglo XIV.

Otros aspectos iconográficos recogen las figuras de Santos devotos de la Virgen y también venerables escritores que habían defendido y propagado su culto. Finalmente el arzobispo incluyó en la capilla una serie de representaciones de Santos que eran de su particular devoción. 


\section{LÁMINA I}

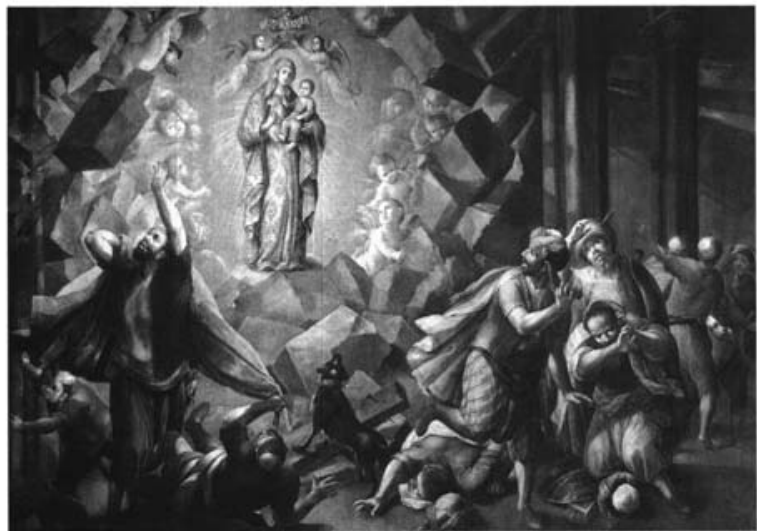

Domingo Martinez. La caída del muro que ocultaba la imagen de la Virgen. Sevilla. Catedral.

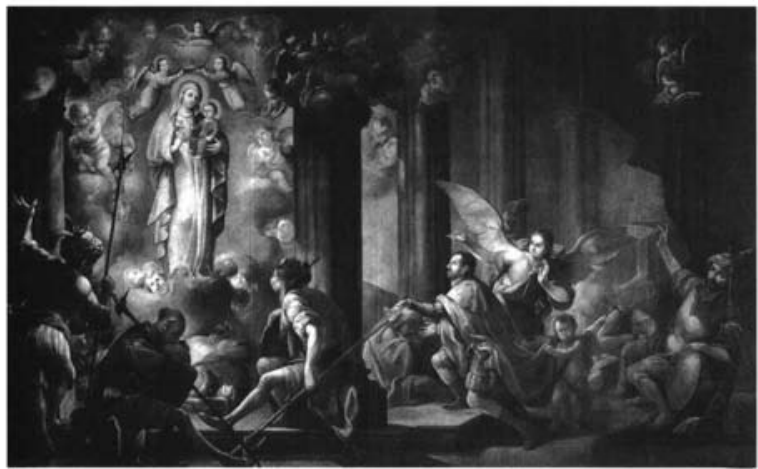

Domingo Martinez. La visita nocturna de San Fernando a la Virgen. Sevilla. Catedral. 


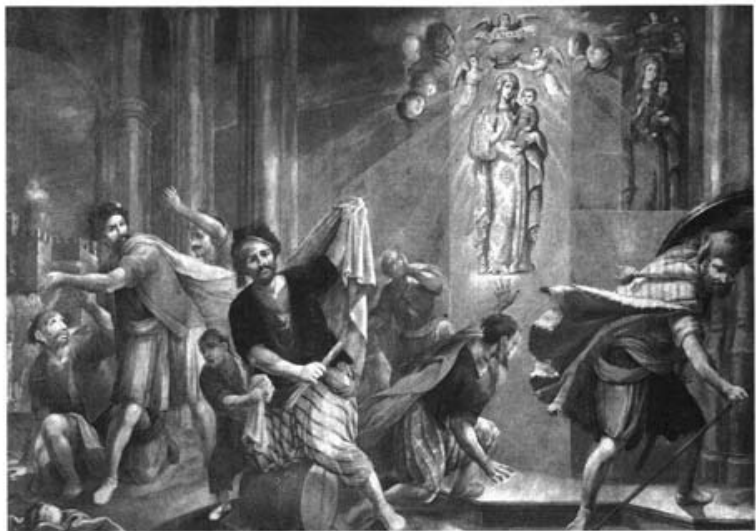

Domingo Martinez. La aparición de la Virgen a los musulmanes a través del muro que la ocultaba. Sevilla. Catedral.

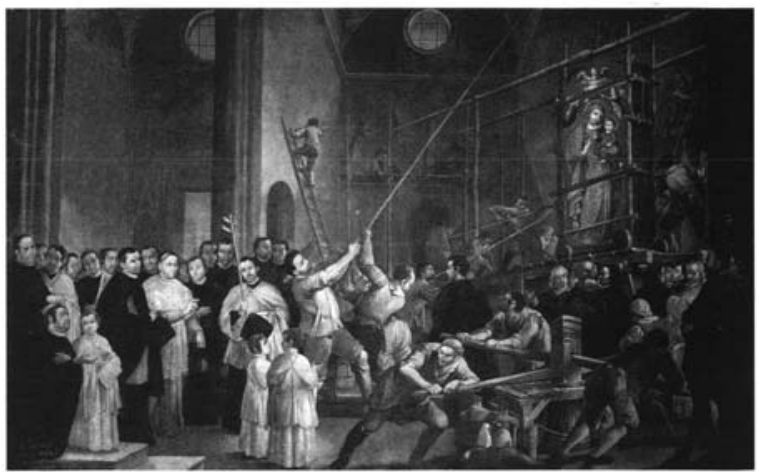

Domingo Martinez. La translación de la imagen de la Virgen. Sevilla. Catedral. 


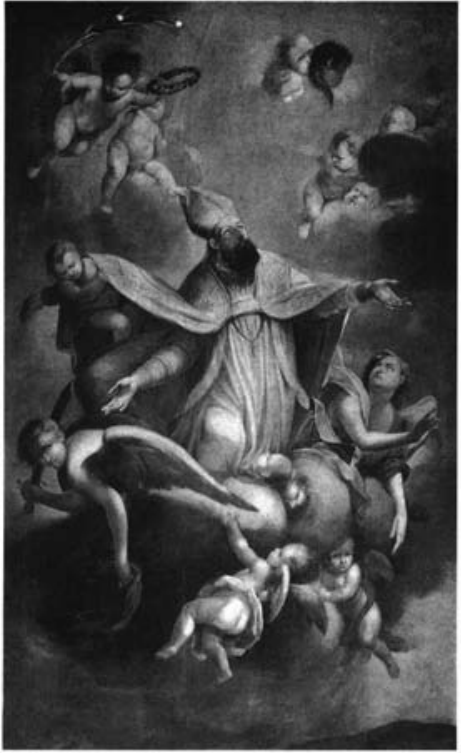

Domingo Martinez. San Laureano, Sevilla. Catedral

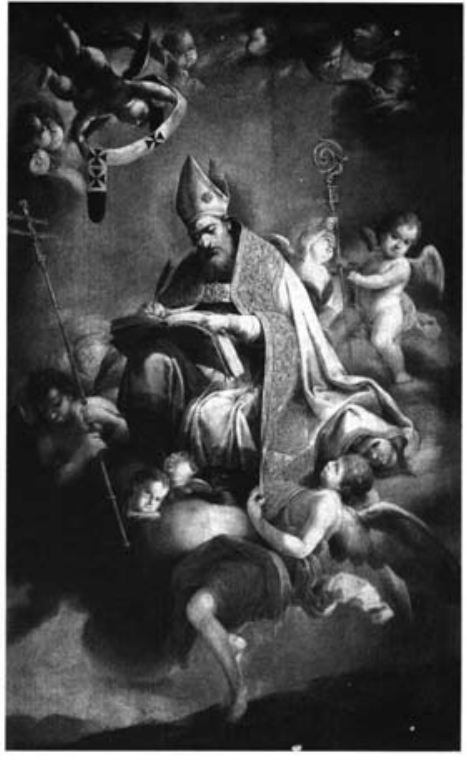

Domingo Martinez. San Isidoro, Sevilla, Catedral. 
LAMINA IV

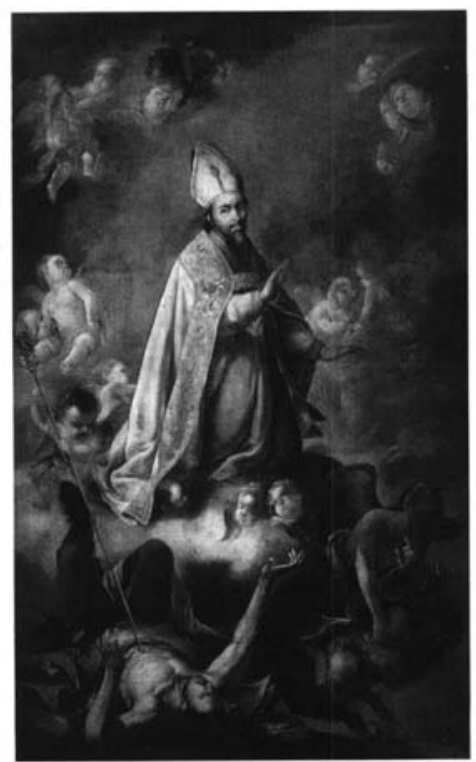

Domingo Martinez. San Leandro. Sevilla. Catedral.

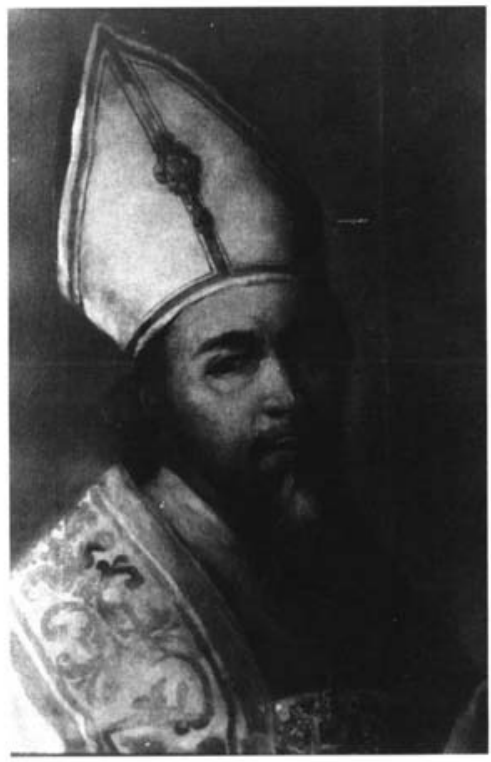

Domingo Martinez. San Leandro (detalle). Sevilla. Catedral. 


\section{LAMINA V}

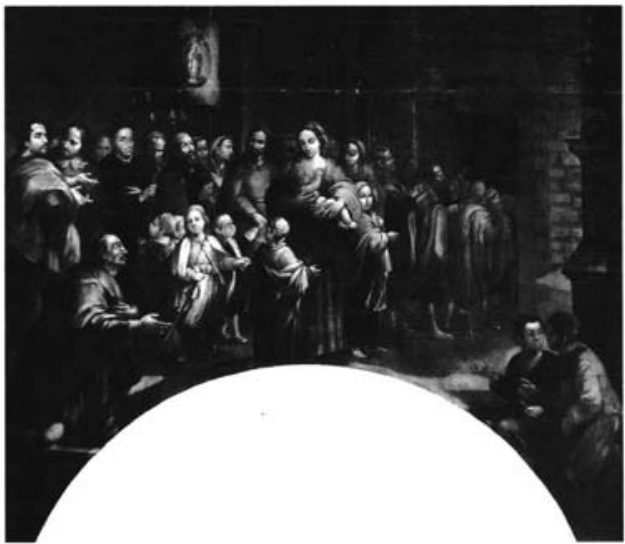

Domingo Martínez. El Venerable Contreras presentando cautivos redimidos a la Virgen. Sevilla. Catedral.

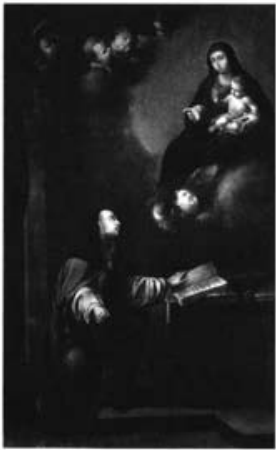

Domingo Martínez. Sor Maria de Agreda. Sevilla. Catedral.

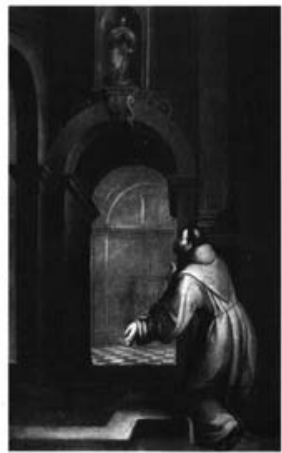

Domingo Martinez. Juan Duns Escoto. Sevilla. Catedral. 